Tropical Journal of Pharmaceutical Research October 2013; 12 (5): 771-776

ISSN: $1596-5996$ (print); 1596-9827 (electronic)

(C) Pharmacotherapy Group, Faculty of Pharmacy, University of Benin, Benin City, 300001 Nigeria.

All rights reserved.

Available online at http://www.tjpr.org

Original Research Article

http://dx.doi.org/10.4314/tjpr.v12i5.17

\title{
High Performance Liquid Chromatographic Determination of Phenolic Compounds in Propolis
}

\author{
Li Yang ${ }^{1,3}$, Qing-Hua Yan ${ }^{2}$, Jin-You Ma ${ }^{1}$, Qing Wang ${ }^{1}$, Jian-Wei Zhang ${ }^{1}$ and Guo- \\ $\mathrm{Xi} \mathrm{Xi}^{3, *}$ \\ ${ }^{1}$ Department of Experimental Center, Henan Institute of Science and Technology, ${ }^{2}$ Department of Life Science and Technology, \\ Xinxiang Medical University, Xinxiang, Henan 453003, ${ }^{3}$ School of Environment, Henan Normal University. Key Laboratory for \\ Yellow River and Huai River Water Environment and Pollution Control, Ministry of Education. Henan Key Laboratory for \\ Environmental Pollution Control, Xinxiang, Henan 453007, PR China.
}

*For correspondence: Email: syzxhome@163.com; Tel: +86-373-3040746

Received: 6 November 2012

Revised accepted: 10 June 2013

\begin{abstract}
Purpose: To develop a simple, precise and rapid high-performance liquid chromatographic technique coupled with photodiode array detection (DAD) method for the simultaneous determination of rutin, quercetin, luteolin, genistein, galangin and curcumin in propolis.

Methods: Ultrasound-assisted extraction was applied to isolate six antioxidant phenolic compounds from propolis samples. Chromatographic separation was performed using an Eclipse XDB-C18 column (150 $\mathrm{mm} \times 4.6 \mathrm{~mm}, 5 \mu \mathrm{m}$ ) by isocratic elution at $25^{\circ} \mathrm{C}$. The mobile phase consisted of phosphate buffered saline $(\mathrm{pH}=4.5)$ and methanol $(40 / 60, \mathrm{v} / \mathrm{v})$. The flow rate was set at $0.8 \mathrm{ml} / \mathrm{min}$ and the effluent was monitored using a DAD set at $260 \mathrm{~nm}$.

Results: Excellent linear correlation coefficient was observed in the range of 0.9977 to 0.9997 . The reproducibility of the method was $1.58 \%$ (RSD) and accuracy was confirmed with average recovery ranging from 95.71 to $104.26 \%$. Six antioxidant phenolic compounds in propolis samples were successfully determined within 50 min.

Conclusion: The proposed isocratic LC method gave good separation and accurate determination of rutin, quercetin, luteolin, genistein, galangin and curcumin in propolis. The proposed method showed good sensitivity, linearity, repeatability and accuracy.

Keywords: Propolis, Rutin, Quercetin, Luteolin, Genistein, Galangin, Curcumin, HPLC.

Tropical Journal of Pharmaceutical Research is indexed by Science Citation Index (SciSearch), Scopus, International Pharmaceutical Abstract, Chemical Abstracts, Embase, Index Copernicus, EBSCO, African Index Medicus, JournalSeek, Journal Citation Reports/Science Edition, Directory of Open Access Journals (DOAJ), African Journal Online, Bioline International, Open-J-Gate and Pharmacy Abstracts
\end{abstract}

\section{INTRODUCTION}

Honey is a natural product increasingly gaining the appreciation of consumers due to its special nutritional and pharmacological properties. From the chemical point of view, honey is a complex mixture of sugars. Its composition depends strongly on the plant species from which the nectar or honey dew has been collected as well as on other factors such as environmental conditions and climate [1]. In recent decades, the analysis of honey flavonoids has been studied as markers of their floral and geographical origin and quality. It was found that hesperetin and quercetin were useful flavonoid markers for citrus honey and sunflower honey, respectively [2].

Propolis, the technical name for bee bread or hive dross, is a natural substance collected by honeybees from buds and exudates of trees and 
plants. Propolis is thought to be of very complex, but more or less constant chemistry. Beeswax is one of its main components (30 \%) but collection of natural substances from tree buds and young branches, and the partial modification of these by bee secretions, lead to the incorporation and concentration by propolis of hundreds of other components (e. g. phenolics), hence its 50-55 \% resin content. Essential oils (8-10 \%) and pollen (5\%) complete the list of major constituents. Some of these components, albeit as minor individual components, have strong biological activity as microbiocides. Flavonoids (e. g. galangin) and phenolcarboxylic acids (e. g. diphenylhydroxycinnamic acid) are examples of these natural antibiotics [3]. Propolis has been used for a long time as a folk medicine to treat a lot of diseases. In the literature, propolis has been associated with various pharmacological activities such as antimicrobial, antiparasitic, antiviral, anti-inflammatory, anti-carcinogenetic and antioxidant activities [4, 5]. Recently, inclusion of propolis solutions in the daily diet has gained importance worldwide in view of its protective role against oxidative damage caused by free radicals which are associated with atherosclerosis, diabetes, and cancer [6]. Furthermore, flavonoids have been described as the main group of phenolic compounds responsible for the antioxidant activity of the propolis, and its activity could also be associated with their degree of polymerization [7].

Many different methods have been developed for determining the representative chemical components in honey and propolis. Highperformance liquid chromatography with diode array (DAD), mid-infrared spectrometry, and electrochemical detection are the most commonly techniques used to analyse flavonoids [8-10]. Recently, LC-MS has also been successfully employed for the identification of phenolic compounds in food samples [11], however this equipment is very expensive and is not common in some control laboratories. The use of UV-Vis and HPLC detector in series could be an excellent alternative when a LC-MS is not available. Taking into account the physicochemical properties of the target compounds, high performance liquid chromatography is an effective analysis method for the determination of antioxidant phenolic compounds in propolis.

In this work, we report for the first time the simultaneous analysis of antioxidant phenolic compounds from propolis samples by on line HPLC coupled with DAD detectors. The aim of this study was to develop a simple, fast and affordable HPLC method for separation of rutin, quercetin, luteolin, genistein, galangin and curcumin in propolis and other similar samples. The proposed method was validated with respect to linearity, reproducibility, accuracy and recovery.

\section{EXPERIMENTAL}

\section{Chemicals and material}

Methanol (MeOH) was of HPLC grade (Fisher Scientific, Pittsburgh, PA, USA) and was used as received. Ultra-high quality water System (SG Ultra Clear System, Wasseraufbereitung und Regenerierstation $\mathrm{GmbH}$, Germany) was used to produce ultra pure water with specific conductivity as low as $0.055 \mu \mathrm{S} / \mathrm{cm}$ for HPLC analysis. Standards of rutin, quercetin, Iuteolin, genistein, galangin and curcumin were purchased from from Sigma (Steinheim, Germany). Sodium dihydrophosphate and disodium hydrogen phosphate were of analytical grade and used for the preparation of the mobile phase.

Propolis samples (acacia honey) were purchased from a traditional Chinese medicine store in Xinxiang, China and identified by Li-Juan Yang at School of Pharmacy of Xinxiang Medical University.

\section{Instruments and conditions}

A Finnigan series LC-DAD system consisting of a surveyor pump plus (Thermo Finnigan, MA, USA), a diode array detector system (Thermo Finnigan, MA, USA), a column oven, a six-way rotary valve for sample introduction with a $20 \mu \mathrm{l}$ sample loop and controlled by a Xcalibur software, were used.

An EclipseXDB-C18 (150 mm×4.6 mm, $5 \mu \mathrm{m})$ was used as analytical column for LC separation. The mobile phase was a mixture of phosphate buffered saline $(\mathrm{pH}=4.5)$ in water and methanol $(40: 60, v / v)$ used in isocratic mode with a flow rate of $0.8 \mathrm{ml} \mathrm{min}^{-1}$. Prior to use, all mobile phases were passed through a $0.45 \mu \mathrm{m}$ membrane filter and degassed under vacuum. The column temperature was set at $25^{\circ} \mathrm{C}$, and the injection volume was $20 \mu \mathrm{l}$. For DAD, the wavelength was set at $260 \mathrm{~nm}$ for the quantitative analysis of rutin, quercetin, luteolin, genistein, galangin and curcumin compounds.

\section{Preparation of standard solutions}

Each $0.016 \mathrm{~g}$ pure standard substance of rutin, quercetin, luteolin, genistein, galangin and curcumin was accurately weighted transferred to 
a $1000 \mathrm{~mL}$ volumetric flask and made up to 1000 $\mathrm{mL}$ with methanol. Then, $0.00,0.5,1.00,2.00$, $4.00,8.00$ and $10.00 \mu \mathrm{g} / \mathrm{mL}$ mixed standard solutions were prepared by stepwise dilution 16 $\mu \mathrm{g} / \mathrm{ml}$ mixed standard stock solution with phosphate buffered saline $(\mathrm{pH}=4.5)$ and methanol $(40 / 60, v / v)$. These standard solutions were stored at $4{ }^{\circ} \mathrm{C}$.

\section{Sample preparation}

In order to remove the beeswax of propolis samples, $5.00 \mathrm{~g}$ of propolis was cut into small pieces by an operating scissors and diluted in 10 $\mathrm{ml}$ of water. The resulting solution was heated at $70{ }^{\circ} \mathrm{C}$ for $40 \mathrm{~min}$ in a thermostatic water bath system and filtered to yield the refined propolis. This was then placed in a constant temperature drying oven set at $80{ }^{\circ} \mathrm{C}$ until the weight was constant. The dried refined propolis samples were homogenized using an agate homogenizer and stored in sealed glass vials until analysis.

In order to extract antioxidant phenolic compounds from propolis samples, $3.50 \mathrm{~g}$ of the dried refined propolis was immersed in $10 \mathrm{ml}$ of $80 \%$ methanol for $24 \mathrm{~h}$, and the resulting solution was treated using ultrasound-assisted extraction procedure two times, each time for 20 min. The combined extract was evaporated to dryness in a rotary evaporator at $65^{\circ} \mathrm{C}$, and the residue was reconstituted with $100 \mathrm{ml}$ of mobile phase, filtered through a $0.45 \mu \mathrm{m}$ syringe filter and injected into HPLC system.

\section{RESULTS}

\section{Chromatographic conditions}

All the standards were separated within 50 min and showed good resolution between matrix and analyte peaks. Fig 1 shows the chromatogram of mixed standard solution and propolis samples.

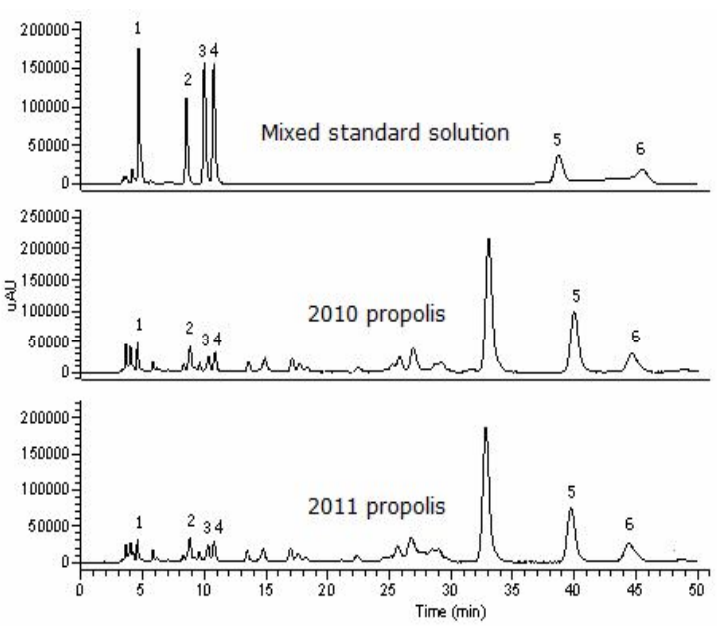

Fig 1: Chromatograms of mixed standard solution and propolis samples of rutin (1) (4.66 min), quercetin (2) (8.54 min), luteolin (3) (9.99 min), genistein (4) (10.75 min), galangin (5) (38.74 min) and curcumin (6) (45.51 $\min$ )

\section{Detection wavelength}

Optimization of an appropriate detection wavelength was of great importance to ensure precise and accurate detection of rutin, quercetin, luteolin, genistein, galangin and curcumin. The scanned UV spectra of all the compounds between $200-600 \mathrm{~nm}$ by diode array detector under the chromatographic conditions are shown in Fig. 2. Rutin, quercetin, luteolin and galangin absorbed at 206, 260 and $354 \mathrm{~nm}$. Genistein and curcumin respectively absorbed at 209, $260 \mathrm{~nm}$ and 207, $432 \mathrm{~nm}$. All the components absorbed strongly at $260 \mathrm{~nm}$. Considering that the condition of chromatography developed should be adapted for quantitative analysis of the six antioxidant phenolic compounds, optimization of detection wavelength of the chromatograms was chosen by monitoring UV absorption at $260 \mathrm{~nm}$.

Table 1: Linearity and detection limits for six analytes

\begin{tabular}{|c|c|c|c|c|}
\hline Compound & $\begin{array}{l}\text { Calibration equation } \\
\qquad Y=a+b X^{a}\end{array}$ & Correlation coefficient $\left(r^{2}\right)$ & $\begin{array}{l}\operatorname{LOD}^{b} \\
(\mu \mathrm{g} / \mathrm{ml})\end{array}$ & $\underset{(\mu \mathrm{g} / \mathrm{ml})}{\mathrm{LOQ}^{\mathrm{b}}}$ \\
\hline Rutin & $Y=36233.2 X+6750.53$ & 0.9984 & 0.06 & 0.22 \\
\hline Quercetin & $Y=61003.4 X+3460.27$ & 0.9997 & 0.09 & 0.31 \\
\hline Luteolin & $Y=63762 X-7488.28$ & 0.9991 & 0.06 & 0.20 \\
\hline Genistein & $Y=154548 X+8289.65$ & 0.9977 & 0.15 & 0.50 \\
\hline Galangin & $Y=32012 X-4700.6$ & 0.9986 & 0.11 & 0.42 \\
\hline Curcumin & $Y=38245.1 X+625.434$ & 0.9997 & 0.83 & 2.67 \\
\hline
\end{tabular}




\section{Reproducibility of the proposed method}

Further experiments were performed to assess the reproducibility of the method. Five consecutive replicates of the analysis on the same propolis sample were determined under optimum conditions and the relative standard deviations were calculated. The results show that the RSD of the method was $1.58 \%(n=5)$, which indicates that the proposed method has good reproducibility.

\section{Analysis of real samples}

The chromatograms of samples are shown in Fig 1 under the most appropriate chromatographic separation conditions. To evaluate the efficiency of the proposed method in real samples, the method was successfully applied to assay of rutin, quercetin, luteolin, genistein, galangin and curcumin in propolis samples. Accuracy was estimated by recovery tests performed on each analyte. The spiked 2010 and 2011 propolis samples were then prepared and analysed by the proposed HPLC-DAD method. The results are shown in Table 2. The average recoveries are in the range $95.71-104.26 \%$ (RSD $<4.96$ $\%$ ), the results showed very good recoveries for the proposed analytical method.

\section{Quantitative analysis of phenolic compounds contained in propolis}

The results of the average concentrations of rutin, quercetin, luteolin, genistein, galangin and curcumin in 2010 and 2011 propolis are presented in Table 3. It is observed that from the test results that the contents of antioxidant phenolic compounds in propolis samples presented a wide variability. For the majority of antioxidant phenolic compounds, quercetin, genistein and galangin contents were found to be higher in 2010 propolis than in 2011 propolis. Rutin concentration in both age samples indicated similar levels. Luteolin and curcumin content in 2011 propolis was relatively higher than in 2010 propolis. The antioxidant phenolic compounds in propolis samples are important for nutritional value, and their levels may vary due to geographic origin of propolis, etc.

\section{Validation of the method}

The HPLC method was validated by defining the linearity, limits of detection (LOD) and limits of quantification (LOQ), reproducibility, accuracy and recovery.

\section{Calibration curves for phenolics, LOD and LOQ}

The calibration curve of the individual antioxidant phenolic compound was based on these six concentrations of standard solutions. The peak area values were the average values of three replicate injections. The results of calibration curves and correlation coefficients are summarized in Table 1, and a good correlation was found between the peak area $(Y)$ and the concentrations $(X)\left(R^{2}>0.9977\right)$ for all the compounds in the range of concentration tested at $260 \mathrm{~nm}$.

Table 2: Results of the accuracy of the method $(n=3)$

\begin{tabular}{lcccccc}
\hline Compound & $\begin{array}{c}\text { Propils } \\
(\mathbf{y e a r})\end{array}$ & $\begin{array}{c}\text { Blank } \\
(\boldsymbol{\mu g} / \mathbf{m l})\end{array}$ & $\begin{array}{c}\text { Added } \\
(\boldsymbol{\mu} \mathbf{g} / \mathbf{m l})\end{array}$ & $\begin{array}{c}\text { Detected } \\
(\boldsymbol{\mu g} / \mathbf{m l})\end{array}$ & $\begin{array}{c}\text { Average recovery } \\
(\%)\end{array}$ & $\begin{array}{c}\text { RSD } \\
(\%)\end{array}$ \\
\hline Rutin & & 19.88 & 20 & 39.50 & 98.12 & 1.59 \\
Quercetin & & 32.16 & 20 & 52.63 & 102.34 & 2.38 \\
Luteolin & 2010 & 58.50 & 50 & 107.33 & 97.65 & 3.24 \\
Genistein & & 42.22 & 50 & 90.51 & 96.58 & 1.78 \\
Galangin & 139.25 & 100 & 243.51 & 104.26 & 3.14 \\
Curcumin & & 0.70 & 0.50 & 1.18 & 95.71 & 4.96 \\
Rutin & & 19.80 & 20 & 39.47 & 98.37 & 4.72 \\
Quercetin & 27.68 & 30 & 58.48 & 102.68 & 2.94 \\
Luteolin & 2011 & 62.05 & 50 & 112.69 & 101.29 & 1.93 \\
Genistein & 37.99 & 50 & 86.09 & 96.21 & 3.68 \\
Galangin & & 110.65 & 100 & 214.61 & 103.96 & 2.81 \\
Curcumin & 6.94 & 5 & 11.89 & 99.01 & 2.40 \\
\hline
\end{tabular}

Table 3: Average concentrations of antioxidant phenolic compounds in propolis $(n=3)$

\begin{tabular}{cccccccc}
\hline Sample & $\begin{array}{c}\text { Year of } \\
\text { production }\end{array}$ & $\begin{array}{c}\text { Rutin } \\
(\mathbf{m g} / \mathbf{g})\end{array}$ & $\begin{array}{c}\text { Quercetin } \\
(\mathbf{m g} / \mathbf{g})\end{array}$ & $\begin{array}{c}\text { Luteolin } \\
(\mathbf{m g} / \mathbf{g})\end{array}$ & $\begin{array}{c}\text { Genistein } \\
(\mathbf{m g} / \mathbf{g})\end{array}$ & $\begin{array}{c}\text { Galangin } \\
(\mathbf{m g} / \mathbf{g})\end{array}$ & $\begin{array}{c}\text { Curcumin } \\
(\mathbf{m g} / \mathbf{g})\end{array}$ \\
\hline Propis & 2010 & 0.3976 & 0.6433 & 1.170 & 0.8445 & 2.785 & 0.0140 \\
Propis & 2011 & 0.3960 & 0.5536 & 1.241 & 0.7598 & 2.213 & 0.1388 \\
\hline
\end{tabular}




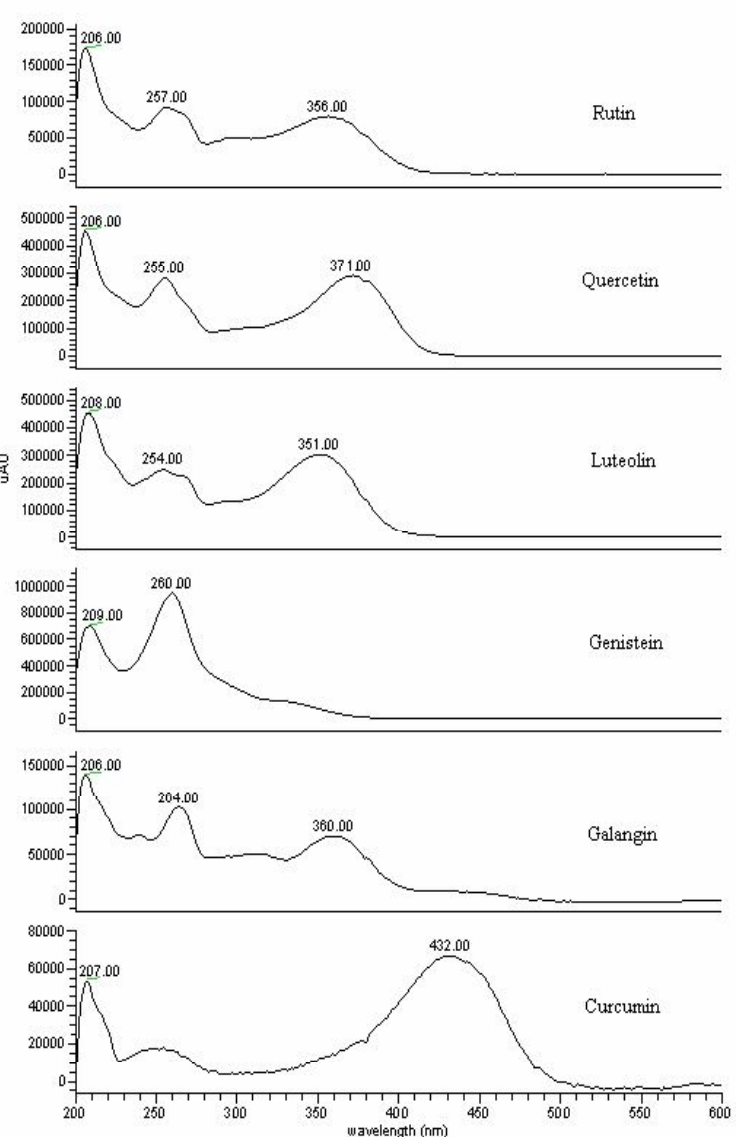

Fig 2: The total UV spectra of rutin, quercetin, luteolin, genistein, galangin and curcumin at $200-600 \mathrm{~nm}$

LOD and LOQ were usually calculated using 3 $\mathrm{SD} / \mathrm{b}$ and $10 \mathrm{SD} / \mathrm{b}$ (SD is the standard deviation of the curve and $b$ is the slope of the curve). In our work, detection and quantification limits were calculated by decreasing the concentration of the single standard solution to the smallest detectable peak. This concentration was obtained as the detection and quantification limits, respectively. LOD and LOQ values of six antioxidant phenolic compounds are shown in Table 1.

\section{DISCUSSION}

\section{Optimization of antioxidant phenolic compounds extraction}

Propolis ethanolic solutions are the most used propolis products on the market for the treatment of minor ulcers in the mouth, angina, thrush or skin infections [12]. It is generally accepted that the solvent of choice for the extraction of biologically active components of propolis (mainly phenolics, including different types of flavonoids) is $70 \%$ ethanol [13]. In order to obtain optimization of extract conditions, the use of a suitable extract solution required an optimum organic solvent composition with good dissolving properties for antioxidant phenolic compounds without risking the elution of analytes. Methanol, ethanol and acetonitrile were examined as extracting solvents. Because methanol provided the best HPLC separation conditions, it was selected for elution in most research studies. Methanol was chosen as the extracting solvent in this study.

Recently, microwave assisted extraction (MAE) and ultrasonic extraction (UE) were introduced among the most promising for the extraction of natural products instead of the traditional maceration method. The advantages of the procedure (ultrasonic extraction) reduced extraction times significantly and increased extraction yields, and produced fast and efficient extraction of organic compounds from solid matrices [14]. A new sample pretreatment method based on ultrasound-assisted extraction in methanol was developed for the extraction of rutin, quercetin, luteolin, genistein, galangin and curcumin in propolis samples. Since antioxidant phenolic compounds in propolis may be oxidized in open air or heating under ambient conditions, propolis samples and the mixed standard solutions should not be heated at a high temperature and stored for a long time. Propolis samples should be handled at low temperature or cold storage.

\section{Optimization of chromatographic conditions}

As there are no published LC methods for determining rutin, quercetin, luteolin, genistein, galangin and curcumin simultaneously in propolis so far, we have decided to optimize proposed chromatographic methods for the analysis of flavones and isoflavones in propolis samples. The optimization procedure was focused on the analytical column, the mobile phase composition and the separation temperature.

C18 analytical column presented a good stability in a wide $\mathrm{pH}$ range and has provided good results in previously published works for determining flavones and isoflavones in honey or propolis [15], therefore, we selected an EclipseXDB-C18 $(150 \mathrm{~mm} \times 4.6 \mathrm{~mm}, 5 \mu \mathrm{m})$. Because with shorter columns $(50 \mathrm{~mm})$, it was not possible to separate mixed standards which eluted at the same time; however, with longer columns $(250 \mathrm{~mm})$, the analysis time was unnecessarily long. Hence, the shorter column was selected as analytical column to perform the experiments.

The mobile phase mixtures of diluted acidic or alkaline solutions with organic solvents were the most widely used mobile phase during 
chromatographic separation, such as formic and acetic acids, phosphoric acid, ammonium acetate, methanol and acetonitrile. A mixture of phosphoric acid and methanol was used as mobile phase in isocratic mode during the analytical process. If the concentration of phosphoric acid was too high, the matrix of the stationary phase of the chromatographic column would be damaged.

In the beginning, $0.4 \%$ phosphoric acid and methanol $(60: 40, \mathrm{v} / \mathrm{v})$ were used as mobile for the separation of target compounds. The results showed a worse degree of separation between matrix and some analyte peaks, and the symmetry of the peaks was poor, and some analytes were not displayed in the chromatogram. We decided to optimize the mobile phase composition by adjusting the $\mathrm{pH}$ value of phosphoric acid using sodium dihydrophosphate and disodium hydrogen phosphate.

When the $\mathrm{pH}$ of phosphoric acid was adjusted to 4.5 , the mobile phase used was mixture of phosphate buffered saline $(\mathrm{pH}=4.5)$ and methanol $(60: 40, \mathrm{v} / \mathrm{v})$. The flow rate was maintained at $0.8 \mathrm{ml} / \mathrm{min}$, the injection volume was $20 \mu \mathrm{l}$, and the temperature was set at $25^{\circ} \mathrm{C}$. Using this condition, all the compounds were separated within $50 \mathrm{~min}$ and showed a good resolution between matrix and analyte peaks.

In order to understand the influence of temperature on the separation, a temperature test on the chromatographic column was carried out by varying the temperature between 25 and $45^{\circ} \mathrm{C}$ in $5^{\circ} \mathrm{C}$ steps. It was observed that there was a variation in retention time and signal-noise ratio as column temperature changed. As was expected, with increase in temperature of chromatographic column, retention time slightly decreased. However, some of the analyte peaks were not separated completely because their retention times were too close. The best results were achieved at $25^{\circ} \mathrm{C}$ because the peaks were narrow and the signal to noise ratio was reduced.

\section{CONCLUSION}

Ultrasound-assisted extraction is a simpler and more effective extraction method for the isolation of antioxidant phenolic compounds in propolis. The results show a wide range in the concentration of antioxidant phenolic compounds in the propolis.samples. For the majority of antioxidant phenolic compounds, age difference had no major effect on their contents. The developed isocratic LC method allowed for the separation and accurate determination of rutin, quercetin, luteolin, genistein, galangin and curcumin in propolis within $50 \mathrm{~min}$. The proposed method also showed good sensitivity, linearity, repeatability and accuracy.

\section{REFERENCES}

1. Rodríguez-Gonzalo E, García-Gómez D, CarabiasMartínez R. A confirmatory method for the determination of phenolic endocrine disruptors in honey using restricted-access material-liquid chromatography-tandem mass spectrometry. Anal Bioanal Chem 2010; 398: 1239-1247.

2. Hadjmohammadi MR, Nazari S, Kamel K. Determination of flavonoid markers in honey with SPE and LC using experimental design. Chromatographia 2009; 69: 1291-1297.

3. Fontana JD, Passos $M$, dos Santos MHR, Fontana CK, Oliveira $B H$, Schause L, Pontarolo $R$, Barbirato MA, Ruggiero MA. Lancas FM. Lancas FM. Profiling propolis flavonoids by means of micellar electrokinetic capillary chromatography. Chromatogra phia 2000; 52: 147-151.

4. Cardoso RL, Maboni F, Machado G, Alves SH, de Vargas AC. Antimicrobial activity of propolis extract against Staphylococcus coagulase positive and Malassezia pachydermatis of canine otitis. Vet Microbiol 2010; 142: 432-434.

5. Duran N, Muz M, Culha G, Duran G, Ozer B. GC-MS analysis and antileishmanial activities of two Turkish propolis types. Parasitol Res 2011; 108: 95-105.

6. Butnariu MV, Giuchici CV. The use of some nanoemulsions based on aqueous propolis and lycopene extract in the skin's protective mechanisms against UVA radiation. J Nanobiotech 2011; 9: 3-9.

7. Bonvehí JS, Gutiérrez AL. Antioxidant activity and total phenolics of propolis from the Basque Country (Northeastern Spain). J Am Oil Chem Soc 2011; 88: 1387-1395.

8. Luoa C, Zoua $X, L i Y$, Sun $C$, Jiang $Y, W u Z$. Determination of flavonoids in propolis-rich functional foods by reversed phase high performance liquid chromatography with diode array detection. Food Chem 2011, 127(1): 314-320.

9. Ruoff K, Iglesias MT, Luginbühl W, Bosset JO, Bogdanov $\mathrm{S}$, Amadò R. Quantitative analysis of physical and chemical measurands in honey by mid-infrared spectrometry. Eur Food Res Technol 2006; 223: 2229.

10. Cao W, Liu H, Cheng N, Gao H, Wang B, Zheng J. LC with electrochemical detection for analysis of caffeic acid and caffeic acid phenyl ester in propolis. Chromatographia 2011; 73: 1864-1867.

11. Pellati F, Orlandini G, Pinetti D, Benvenuti S. HPLC-DAD and HPLC-ESI-MS/MS methods for metabolite profiling of propolis extracts. J Pharmaceut Biomed 2011; 55: 934-948.

12. Kosalec I, Pepeljnjak S, Bakmaz M, Vladimir-kne S. Flavonoid analysis and antimicrobial activity of commercially available propolis products. Acta Pharmaceut 2005; 55: 423-430.

13. Cunha IBS, Sawaya ACHF, Caetano FM, Shimizu MT, Marcucci MC, Drezza FT, Povia GS, Carvalho PO. Factors that influence the yield and composition of Brazilian propolis extracts. J Brazil Chem Soc 2004;15: 964-970.

14. Trusheva B, Trunkova D, Bankova V. Different extraction methods of biologically active components from propolis: a preliminary study. Chem Cent J 2007; 1: 13-16.

15. Nozal MJ, Bernal JL, Martin MT, Bernal J, Álvaro A, Martín $R$, Higes $M$. Trace analysis of fumagillin in honey by liquid chromatography-diode arrayelectrospray ionization mass spectrometry. J Chromatogr A 2008;1190(1-2): 224-231. 